\title{
Prediction of Surface Roughness Based on Machining Condition and Tool Condition in Boring Stainless Steel-304
}

\author{
G. Balamurugamohanraj ${ }^{*}$, K. Vijaiyendiran', P. Mohanaraman' ${ }^{1}$ and V. Sugumaran ${ }^{2}$ \\ 'Department of Mechanical Engineering, Sri Manakula Vinayagar Engineering College, \\ Mannadipet Commune, Madagadipet, Puducherry - 605107, Tamil Nadu, India; \\ gbmmohanraj@rediffmail.com, vijimech1992@gmail.com, mohanaraman91@gmail.com, \\ ${ }^{2}$ School of Mechanical and Building Sciences (SMBS), VIT University, Chennai Campus, Chennai - 600127, \\ Tamil Nadu, India; v_sugu@yahoo.com
}

\begin{abstract}
Background/Objectives: Modern manufacturing industries aim to increase production rate with less production cost and high quality. To achieve high production rate with minimum cost, machining parameters must be optimized in industries. Therefore, the main objective of this study is to establish the relationship between the influence of cutting parameters and surface roughness in dry boring operation. Methods/Statistical analysis: A full factorial design was used to evaluate the effect of four independent variables (feed rate, spindle speed, depth of cut, tool flank wear). Stainless steel 304 was selected as a work piece due to high hardness, chemical stability and various applications. Carbide tipped tool insert was used for machining. Findings: During machining, Statistical features were extracted from the vibration signal. The extracted statistical features, machining condition and tool flank wear were considered to establish the various surface roughness prediction models. Multilayer perceptron and decision tree models were developed to predict the surface roughness. From these two models, the best suitable prediction model was selected based on maximum correlation coefficient and minimum root mean squared error values. Application/Improvements: The selected best model can be used for variety of machining conditions to predict the surface roughness of the machined surface.
\end{abstract}

Keywords: Cutting Parameters, Decision Tree, Flank Wear, Linear Regression, Vibration Signals

\section{Introduction}

In the manufacturing industry, vibration is induced by the metal cutting process, e.g. turning, milling and boring operations. Turning operations, and especially boring operation, is associated with serious vibration-related problems. Boring is a metal cutting process for producing an internal cylindrical surface with a single point tool. The work piece is rotated by the spindle and the cutting tool is feed either radial, axial or both. Boring is an operation which is used to increase the internal diameter of work material for our convenience. The purpose of boring operation is to produce low surface roughness of the parts. Surface roughness is another important factor to evaluate cutting performance. Proper selection of cutting parameters and tool can produce longer tool life and lower surface roughness. Some researchers have contributed experimental works based on the prediction of the surface roughness from the effect of machining conditions and tool wear. Length of Short tool always provide good surface roughness no matter what cutting parameters level (or) type of boring bar are used, only slight improvement on surface roughness can be achieved by properly controlling cutting speed, feed rate, depth of cut and tool nose radius. The model proposed in boring operation is quite useful since it can be used to help the

${ }^{*}$ Author for correspondence 
machinist set the proper cutting parameter in order to achieve the best surface roughness ${ }^{1}$. A cemented tungsten carbide micro turning tools were fabricated for electric discharging machining method and used for machining brass material. In this machining process circularity of bored holes and surface finish were improved 2 . The effect of vibration on surface roughness of the work piece was analyzed in boring and drilling process with the help Taguchi method and Analysis Of Variance (ANOVA) Surface roughness prediction model was developed in lower cutting speed of AISI316 austenitic stainless steel by using multiple linear regression and Artificial Neural Network (ANN) methods $s^{4}$. The first resonance frequency was estimated in the cutting speed and cutting depth directions and it was obtained by the Euler-Bernoulli model of the boring bar ${ }^{5}$. The tool life was evaluated by analyzing surface roughness, amplitude of work piece vibration and volume of metal removed with the help of Taguchi, ANOVA and Regression analysis- Orthogonal array taguchi design was used to study the influence of machining parameters on material removal rate and cutting force on surface roughness during machining of AISI 304 austenitic stainless steel ${ }^{7}$. The fluid application parameters and tool vibration and cutting performance were investigated during head turning with minimal fluid application $\%$. Back propagation type neural network and taguchi's L25 array were used to predict the surface roughness parameters such an $\mathrm{Ra}, \mathrm{Rz}$ and $\mathrm{Rt}^{9}$. Surface roughness prediction modal was developed based on response surface method to investigate the machining parameters such as feed rate, tool geometry, nose radius and machining time, affecting the roughness of surface produced in dry turning process ${ }^{10}$. In boring operation a shorted tool length always provides good surface roughness than longer tool length by using ANOVA 11 . Machining parameters were optimized in turning operation to reduce the surface roughness by integrating ANN and Genetic Algorithm (GA) approach ${ }^{12}$. Model based on theory are generally not accurate so their improvement with the introduction of additional parameters is examined by researches. The objective of this research is to develop a methodology for predicting the surface roughness and selecting parameters based on effective tools, hence the use of empirical data ${ }^{\frac{13}{3}}$. The influence of different cutting fluids on the wear and the surface roughness were determined when turning AISI 304 austenitic stainless steel ${ }^{14}$. Tool chatter was modeled in turning based on a parametric time-series approach using experimen- tal data for tool vibration. The experimental chatter data were described with the aid of an ARMA model driven by white noise $e^{15,16}$. The stability limit of slender boring bar was investigated experimentally in external longitudinal turning or regenerative cutting conditions at different cutting speed and inclination angles. The vibrations were measured in the cutting speed and cutting depth direction. He developed a two-degrees-of -freedom analytical model of the boring bar with two input forces, one proportional to the variation of chip thickness and the other proportional to the penetration velocity. Stability limits were predicted with the aid of the model; these were then compared with the experimental results ${ }^{17}$. Mean-square value estimates were used to investigate the influence of different cutting data and work-piece materials on the mean-square properties of boring bar vibration. Also, mean-square value estimates may be used to indicate non-stationarities in the second-order properties of the boring vibration as well as provide estimates of the timevarying structure of the mean-square value ${ }^{\frac{18}{}}$. Stationarity tests on boring bar vibration records allow stationarity of these vibrations to be evaluated for different cutting data and work-piece materials $\frac{19,20}{}$.

\section{Experimental Design}

In the experimental design totally sixteen experiments were designed by varying the cutting conditions and two tool conditions. The tool flank wear is $0 \mathrm{~mm}$ and $0.5 \mathrm{~mm}$. The depth of cut is $0.5 \mathrm{~mm}$ and $0.75 \mathrm{~mm}$. The spindle speed is $400 \mathrm{rpm}$ and $600 \mathrm{rpm}$. Feed rate is $0.15 \mathrm{~mm} / \mathrm{rev}$ and $0.25 \mathrm{~mm} / \mathrm{rev}$. The Table 1 shows machining condition and the combinations are arrived from full factorial design.

Table 1. Machining conditions

\begin{tabular}{|l|l|l|l|l|}
\hline $\begin{array}{l}\text { Machining } \\
\text { conditions }\end{array}$ & $\begin{array}{l}\text { Speed } \\
(\mathbf{r p m})\end{array}$ & $\begin{array}{l}\text { Feed } \\
(\mathbf{m m} / \mathbf{r e v})\end{array}$ & $\begin{array}{l}\text { DOC } \\
(\mathbf{m m})\end{array}$ & $\begin{array}{l}\text { Flank Wear } \\
(\mathbf{m m})\end{array}$ \\
\hline M1 & 400 & 0.15 & 0.5 & 0 \\
\hline M2 & 400 & 0.15 & 0.75 & 0 \\
\hline M3 & 400 & 0.25 & 0.5 & 0 \\
\hline M4 & 400 & 0.25 & 0.75 & 0 \\
\hline M5 & 600 & 0.15 & 0.5 & 0 \\
\hline M6 & 600 & 0.15 & 0.75 & 0 \\
\hline M7 & 600 & 0.25 & 0.5 & 0 \\
\hline M8 & 600 & 0.25 & 0.75 & 0 \\
\hline
\end{tabular}




\begin{tabular}{|l|l|l|l|l|}
\hline M9 & 400 & 0.15 & 0.5 & 0.5 \\
\hline M10 & 400 & 0.15 & 0.75 & 0.5 \\
\hline M11 & 400 & 0.25 & 0.5 & 0.5 \\
\hline M12 & 400 & 0.25 & 0.75 & 0.5 \\
\hline M13 & 600 & 0.15 & 0.5 & 0.5 \\
\hline M14 & 600 & 0.15 & 0.75 & 0.5 \\
\hline M15 & 600 & 0.25 & 0.5 & 0.5 \\
\hline M16 & 600 & 0.25 & 0.75 & 0.5 \\
\hline
\end{tabular}

\section{Experimental Setup}

The experimental setup is shown in Figure 1 which consists of an Accelerometer, Data acquisition unit, surface roughness tester, CNC lathe machine - HAAS Automation.

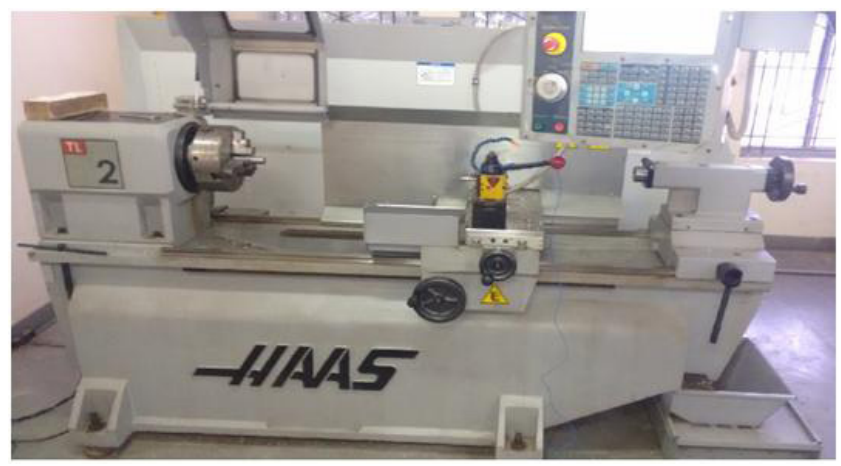

Figure 1. CNC lathe machine.

\subsection{Mounting of Accelerometer and Data Acquisition Card}

The data acquisition cord is used to acquire the vibration signals while machining. The sensor was fixed on the boring bar nearer to the tool post and it was connected to data acquisition card. The data acquisition card was connected to a computer to store the recorded signal in digital form. The arrangement of sensor and tool holder was shown in Figure 2.

\subsection{Tool Preparation}

The carbide tool is mostly used for many machining operation in all the fields of manufacturing industries because it withstands higher temperature than HSS. The carbide tool insert was used for the machining operation with the nose radius of $0.4 \mathrm{~mm}$ and the tool grade is CCMT060204. The tool flank wear was measured by using Tool Makers

Microscope. The carbide insert with tool holder is shown in Figure 3.

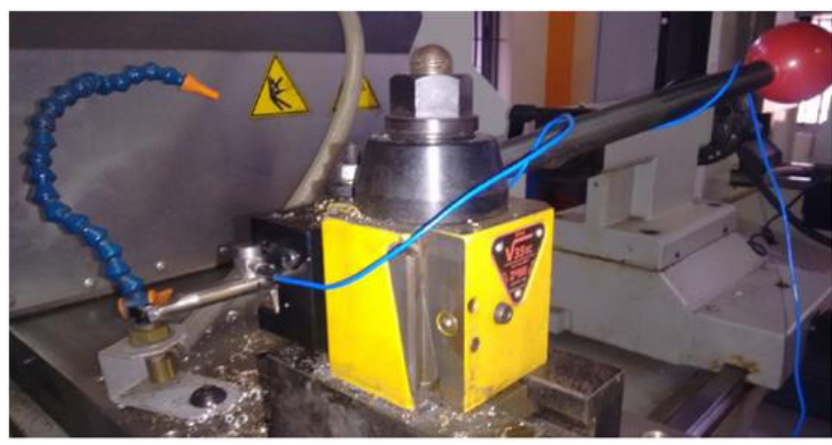

Figure 2. Arrangement of sensor on the boring bar.

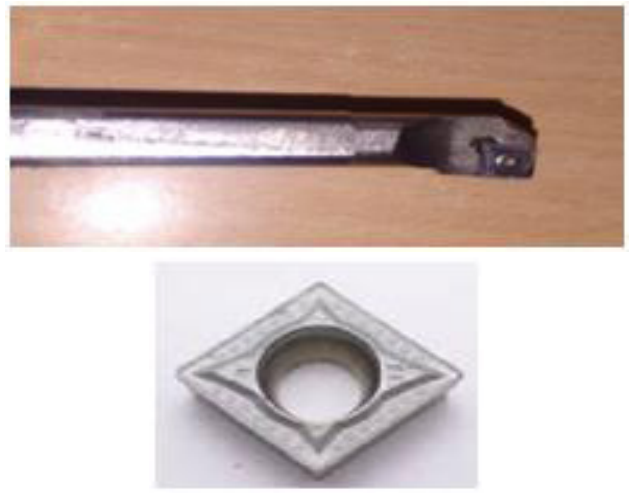

Figure 3. Carbide insert and carbide insert with tool holder.

\subsection{Experimental Procedure}

The machining was done in the $\mathrm{CNC}$ lathe machine, the work piece was fixed in the three jaw chuck, the carbide tool insert was fixed in tool holder and the tool holder was clamped in the tool post. Considering the cutting parameters like spindle speed, feed rate and depth of cut, the boring programme was written in the CNC Lathe machine. As the machining cycle was started, the tool moved forward to the work piece and the material was removed based on feed rate and depth of cut. During machining, the vibration signals were collected using accelerometer sensor and data acquisition card. Finally, it was stored in the computer in digital form. After completing the machining, the surface roughness was measured on the machined surface. This procedure was repeated for sixteen machining conditions.

\subsection{Statistical Features}

The statistical features were taken for this study such as mean, standard error, standard deviation, sample vari- 
ance, kurtosis, skewness, minimum, maximum and sum. Thus the statistical features were calculated for the 200 signals of each machining condition.

\subsection{Methodology}

In order to build a prediction model for the surface roughness, the details about the cutting parameters and the vibration signals are required. The surface roughness of each set of cutting parameters and vibration signals were measured. The cutting parameters and the statistical features of vibration signals were taken as independent variable. The measured Surface roughness $(\mathrm{Ra})$ was taken as dependent variable.

\section{Decision Tree Analysis and Regression Analysis}

A decision is a tree based knowledge representation methodology used to represent classification rules. The various data can be analyzed in the tree basis. The main purpose of a decision tree analysis is to expose the structural information contained in the data.

\subsection{Definition of Decision Tree}

A schematic tree-shaped diagram is used to determine a course of action or show a statistical probability. Each branch of the decision tree represents a possible decision or occurrence. The tree structure shows how one choice leads to the next, and the use of branches indicates that each option is mutually exclusive.

A decision tree is a flowchart-like structure in which each internal node represents a "test" on an attribute (e.g. whether a coin flip comes up heads or tails), each branch represents the outcome of the test and each leaf node represents a class label (decision taken after computing all attributes). The path from root to leaf represents classification rules.

In decision analysis, a decision tree and the closely related influence diagram are used as a visual and analytical decision support tool, where the expected values (or expected utility) of competing alternatives are calculated.

A decision tree consists of 3 types of nodes:

- Decision nodes - commonly represented by squares

- Chance nodes - represented by circles

- End nodes - represented by triangles
Decision trees are commonly used in operations research and operations management. If in practice decisions have to be taken online with no recall under incomplete knowledge, a decision tree should be paralleled by a probability model as the best choice model or online selection model algorithm. Another use of decision tree is a descriptive means for calculating conditional probabilities.

\subsection{Regression Analysis}

The regression analysis is a statistical procedure which shows the relationship between the dependent variables and independent variables. It provides and estimates the values of the dependent variable from the values of independent variable. This estimation is the procedures of regression lines. The regression line $\mathrm{X}$ on $\mathrm{Y}$ is $\mathrm{X}=\mathrm{a}+\mathrm{bY}$ and the regression line Yon $\mathrm{X}$ is $\mathrm{Y}=\mathrm{a}+\mathrm{bX}$. The regression equation of $\mathrm{X}$ on $\mathrm{Y}$ is $\mathrm{X}-\mathrm{X}=\mathrm{b}_{\mathrm{xy}}(\mathrm{Y}-\mathrm{Y})$ and the regression equation of $\mathrm{Y}$ on $\mathrm{X}$ is $\mathrm{Y}-\mathrm{Y}=\mathrm{b}_{\mathrm{vr}}(\mathrm{X}-\mathrm{X})$.

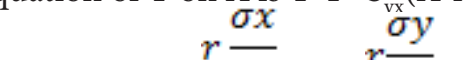

Where $\mathrm{b}_{\mathrm{xy}}=r \overline{\sigma y}, \mathrm{~b}_{\mathrm{yx}}=r \overline{\sigma x}$. The variable that are trying to be predicted $(Y)$ is called the dependent (or response) variable. The variable $x$ is called the independent (or predictor, or explanatory) variable. In linear regression the correlation coefficient values and the two variables are treated as equals.

\section{Results and Discussion}

The Figure 4 shows the variation of surface roughness based on flank wear and the surface roughness variation based on machining condition.

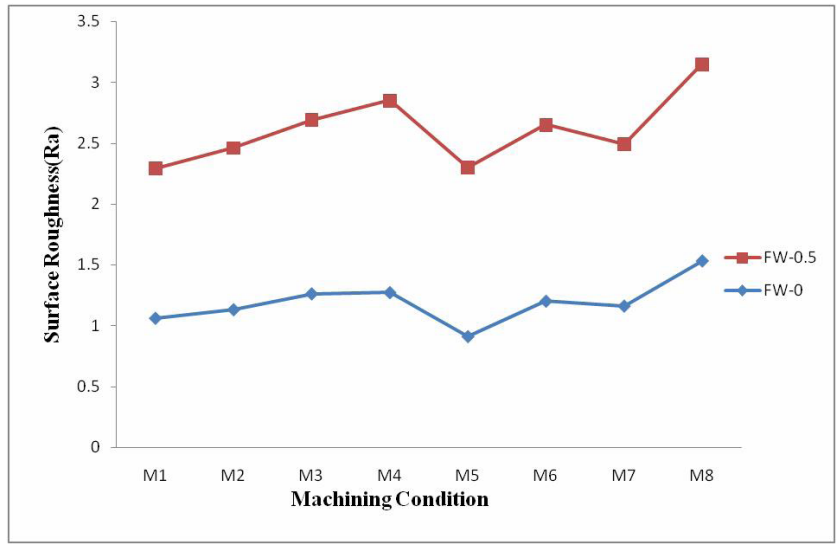

Figure 4. Surface roughness based on flank wear and machining condition. 
From the Figure 4, as the tool wear increases for the particular machining condition the Surface Roughness (Ra) value also increases, and the increasing rate of surface roughness has almost direct proportion with the flank wear. The surface roughness value increases with increase of feed rate and depth of cut and it decreases with increase of spindle speed.

\subsection{Decision Table}

Decision table is a way to decision making that involves considering a variety of conditions and their interrelationships, particular by for complex interrelationships. People use decision table to represent and discover business logic, which ultimately lead to better business.

Scheme: weka.classifiers.rules.DecisionTable -X 1-S Weka.attributeSelection. BestFirst -D 1 -N5"

Instances: 320

Attributes: Speed, Feed, DOC, FW, Mean, Standard Error, Median, Standard Deviation, Sample Variance, Kurtosis, Skewness, Range, Minimum, Sum, Ra

Test mode: 20-fold cross-validation Decision Table

Number of training instances: 320

Number of Rules: 39

Non matches covered by Majority class.

Best first.

Start set: no attributes

Search direction: forward

Stale search after 5 node expansions

Total number of subsets evaluated: 113

Merit of best subset found: 0.03

Evaluation (for feature selection): CV (leave one out)

Feature set: 1,2,3,4,11,13,16

\subsection{Linear Regression Model}

Scheme:weka.classifiers.functions.LinearRegression -S 0 $-\mathrm{R} 1.0 \mathrm{E}-8$

Instances: 320

Attributes: Speed, Feed, DOC, FW, Mean, Standard Error, Median, Standard Deviation, Sample Variance, Kurtosis, Skewness, Range, Minimum, Sum, Ra

Test mode: 10 -fold cross-validation

Linear Regression Model

$\mathrm{Ra}=2.8134 \mathrm{Feed}+0.7498 \mathrm{DOC}+0.2607 \mathrm{FW}-2.3608$ Median +0.1435 Sample Variance +0.0661 Kurtosis 0.5688 Skewness -0.0348 Range +0.2289 Minimum + 0.0896 Maximum +0.0011 Sum +0.4833

\section{Conclusion}

1. In this paper, the prediction of surface roughness model was developed by considering cutting parameters like speed, feed rate, depth of cut, flank wear and tool vibration.

2. The analyses models were done by using Decision table and linear regression models. From the analyses, the best model was selected and preferred for prediction of surface roughness based on the maximum Correlation coefficient value and minimum error values of Mean absolute error, Root mean squared error, relative absolute error and Root relative squared error.

3. The Table 2 shows the numerical valves of the various analyses. The correlation coefficient ranges between zero and one. It is believed that the correlation coefficient is one, that model will perfectly matches the experimental data. In this case the error value is very low (or) negligible. From the result, the Decision table model correlation coefficient is close to one than other prediction model. The error values of the Decision table model are minimum when compared with other. From this one can conclude that the Decision table model fits well for prediction of surface roughness. Thus could be used for variety of cutting conditions in industries.

Table 2. Comparative results of prediction models

\begin{tabular}{|l|l|l|}
\hline Parameters & $\begin{array}{l}\text { Decision } \\
\text { Table }\end{array}$ & $\begin{array}{l}\text { Linear } \\
\text { Regression }\end{array}$ \\
\hline Correlation coefficient & 0.9822 & 0.9412 \\
\hline Mean absolute error & 0.0054 & 0.0468 \\
\hline Root mean squared error & 0.0351 & 0.0634 \\
\hline Relative absolute error & $3.52 \%$ & $30.64 \%$ \\
\hline Root relative squared error & $18.67 \%$ & $33.82 \%$ \\
\hline
\end{tabular}

\section{Reference}

1. Yousssef A. Investigation of cutting parameter effects on surface roughness in lathe boring operation by use of a full factorial design. Computers \& Industrial Engineering. 1996; 31(3):645-51.

2. Egashia K, Iwata M, Nomura Y. Boring and face grooving using micro turning tools. CIRP Annals-Manufacturing Engineering. 2011; 60(6);81-4.

3. Chern G, Liang J. Study on boring drilling with vibration cutting. International Journal of Machine Tools \&Manufacture. 2007; 47(6):133-40. 
4. Acayaba GMA, Escalona PMD. Prediction of surface roughness in low speed turning of American Iron and Steel Institute (AISI) 316 austenitic stainless steel. Manufacturing Science and Technology. 2015; 1(2):62-7.

5. Andren, Hakansson L, Brandt A, Claesson I. Identification of dynamic properties of boring bar vibration in a continuous boring operation. Mechanical Systems and Signals Processing. 2004; 18(5):869-901.

6. Rao KV, Murthy BSN, Rao MN. Cutting tool condition monitoring by analyzing surface roughness, Work Piece Vibration and Volume of Metal removed for AISI 1040 Steel in Boring. Measurement. 2013; 46(10):4075-84.

7. Nayak SK, Patro JK, Dewangan S, Gangopadhyay SS. Multiobjective optimization of machining parameters during dry turning of American Iron and Steel Institute (AISI) 304 austenitic stainless steel using grey relational analysis. Procedia Materials Science. 2014; 6(5):701-8.

8. Paul PSS, Varadarajan AS, Gnanadurai RR. Study on the influence of fluid application parameters on tool vibration and cutting performance during turning of hardened steel. Engineering Science and Technology. 2015 Mar; 19:241-53.

9. Das B, Roy S, Rai RN, Saha SC. Studies on effect of cutting parameters on surface roughness $\mathrm{Ol} \mathrm{Al-Cu-Tic} \mathrm{Mmcs:} \mathrm{an}$ ANN approach. Procedia Computer Science. 2015; 45:74552.

10. Qehaja NN, Jakupi KK, Bunjaku AA, Brucj MM, Osmani $\mathrm{HH}$. Effect of machining parameters and machining time on surface roughness in dry turning process. Procedia Engineering. 2015; 100:135-40.

11. Beauchamp Y, Thomas M. Investigation of cutting parameters effects on surface roughness in lathe boring operating by use of a full factorial design. Computers \& Industrial Engineering. 1996; 31(3-4):645-51.

12. Sangwan KS, Saxena SS, Kant G. Optimization of machining parameters to minimize surface roughness using integrated ANN-GA approach. Procedia CIRP. 2015; 29:305-10.

13. Benardos PG, Vosniakos VGC. Predicting surface roughness in machining: a review. International Journal of Machine Tools and Manufacturing. 2003; 43(8):833-44.

14. Anthiony $\mathrm{X}$, Adithan M. Determining the influence of cutting fluids on tool wear and surface roughness during turning of American Iron and Steel Institute (AISI) 304 austenitic stainless steel. Journal of Materials Processing Technology. 2009; 209(2):900-9.

15. Pandit SM, Subramanian TL, Wu W. Modeling machine tool chatter by time series. Journal of Engineering for Industry. 1975; 97(1):211-5.

16. Pandit SM, Subramanian TL, Wu W. Stability of random vibrations with special reference to machine tool chatter. Journal of Engineering for Industry. 1975; 97(1):216-9.

17. Parker EW. Dynamic stability of a cantilever boring bar with machined flats under regenerative cutting conditions. Journal of Engineering for Industry. 1970; 12(1):104-15.

18. Bendat JS, Piersol AG. Random data analysis and measurement procedures. 3rd edition, Wiley, New York; 2000.

19. Sturesson P, Hakansson L, Claesson I. Identification of the statistical properties of the cutting tool vibration in a continuous turning operation - correlation to structural properties. Journal of Mechanical Systems and Signals Processing. 1997; 11(3):459-89.

20. Bendat JS. Random data analysis and measurement procedures. Wiley, New York; 1986. 